\title{
Testes pré-natais não invasivos para rastreio de aneuploidias: revisão baseada na evidência
}

Telma Miragaia, ${ }^{1-2}$ Joana Fechado Nunes, ${ }^{2-3}$ André Forjaz de Sampaio, ${ }^{4-5}$ Sofia Feijó Correia ${ }^{1-2}$

\section{RESUMO}

Objetivos: Comparar a performance, limitações e custo-efetividade do teste pré-natal não invasivo baseado na medição de ácido desoxirribonucleico (ADN) livre fetal com os testes tradicionais em grávidas.

Fontes de dados: Bases de dados Guidelines Finder, TRIP database, CMA Infobase, The Cochrane Library, DARE, Bandolier e PubMed.

Métodos de revisão: Pesquisa de meta-análises (MA), revisões sistemáticas (RS), ensaios clínicos controlados e randomizados (ECR) e guidelines publicados nas línguas inglesa, portuguesa e espanhola, entre janeiro de 2013 e julho de 2018 . Termos utilizados: non-invasive prenatal test e cell-free fetal DNA. Foi utilizada a escala Canadian TASK Force na avaliação dos estudos, atribuição dos níveis de qualidade da evidência e classificação de recomendação. Foram excluídos artigos repetidos ou que não cumpriam os objetivos. O outcome selecionado foi a performance, limitações e custo-efetividade do teste.

Resultados: Obtiveram-se 517 artigos, cumprindo 12 os critérios de inclusão: seis guidelines, duas RS e quatro RS com MA. 0 teste pré-natal não invasivo baseado na pesquisa de ADN livre fetal apresenta melhor performance para as trissomias 21, 18 e 13 que os testes tradicionais. A validade clínica do teste é superior para a trissomia 21. Não é um teste diagnóstico, devendo ser confirmado por teste invasivo, se os resultados forem positivos ou inconclusivos e feito encaminhamento para aconselhamento genético.

Conclusões: O teste pré-natal não invasivo baseado na pesquisa de ADN livre fetal para as trissomias 21, 18 e 13 pode ser uma opção para grávidas de alto risco em vez da amniocentese. Se o teste for positivo ou inconclusivo deve ser confirmado por teste invasivo (II-2A). Apresenta limitações, nomeadamente se a idade gestacional for inferior a 10 semanas, obesidade, gravidez múltipla ou neoplasia materna. Nestes casos, as grávidas devem ser estudadas. Atualmente, o custo-efetividade do rastreio sequencial contingente é incerto e o rastreio universal não é custo-efetivo (III-C).

Palavras-chave: Teste pré-natal não invasivo; ADN livre fetal.

\section{INTRODUÇÃO}

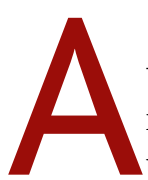

té há poucos anos, o momento do nascimento era uma incógnita, esperando-se ansiosamente pelas palavras "é um menino" ou "é uma menina" e, de seguida, os pais contavam se o bebé tinha todos os dedos das mãos e dos pés. Atualmente, graças aos diversos exames pré-natais disponíveis é possível saber muitas informações antes do parto, nomeadamente malformações causadas por alterações cromossómicas. ${ }^{1-3}$

1. Médica Assistente de Medicina Geral e Familiar.

2. Centro de Saúde de Ponta Delgada, Unidade de Saúde da Ilha de São Miguel.

3. Médica Interna de Medicina Geral e Familiar.

4. Médico Assistente Graduado de Ginecologia e Obstetrícia.

5. Hospital do Divino Espírito Santo (Ponta Delgada).
Prevê-se que a prevalência de malformações fetais seja de cerca de $2 \% .{ }^{4}$ As aneuploidias são alterações cromossómicas onde existe um cromossoma a mais ou a menos. Estima-se que sejam a causa de $6-11 \%$ dos abortos e mortes neonatais e responsáveis por até $0,65 \%$ dos recém-nascidos terem algum problema médico significativo. ${ }^{5} \mathrm{~A}$ aneuploidia mais frequente é a trissomia 21 (síndroma de Down), com uma prevalência de 1/670 e a sua incidência aumenta com a idade materna, sendo de 1/1500 em mulheres com 25 anos e de 1/100 aos 45 anos. ${ }^{6}$

Em Portugal, segundo os dados da European Surveillance of Congenital Anomalies (EUROCAT), a incidência de cromossomopatias varia entre 5-35 casos por 
10.000 nascimentos/ano. A aneuploidia mais frequente em Portugal é a síndroma de Down, com uma prevalência média de 9,19 por cada 10.000 nascimentos nas últimas duas décadas. Apesar de a prevalência de cromossomopatias se manter relativamente constante, o número de crianças nascidas com este problema tem vindo a diminuir, muito à custa das interrupções da gravidez que duplicaram entre 2012 e 2015, provavelmente devido à maior acessibilidade aos diagnósticos pré-natais de aneuploidias. ${ }^{7}$

Inicialmente surgiram os testes invasivos como a amniocentese, biópsia de vilosidades coriónicas e cordocentese, mas que apresentam risco de aborto de 0,1 a 1,3\%. ${ }^{8}$ Nos anos 90 surge o rastreio combinado do primeiro trimestre, que é realizado entre a $11^{\mathrm{a}} \mathrm{e}$ a $13^{\mathrm{a}}$ semanas mais seis dias de gestação e que associa a idade materna à determinação sanguínea materna de duas substâncias fetoplacentárias: fração beta da hormona gonadotrofina coriónica humana ( $\beta$-HCG) e proteínaA plasmática associada à gravidez (PAPP-A) com os marcadores ecográficos, nomeadamente a translucência da nuca e visualização (ou não) dos ossos próprios do nariz. ${ }^{1,48-9}$ Este rastreio pode levar a uma taxa de deteção de trissomia 21 de até $95 \%$, com uma taxa de falsos positivos de $5 \%$. A taxa de deteção de trissomias 18 e 13 poderá chegar, respetivamente, aos $97 \%$ e $92 \%$, de acordo com alguns estudos. Os restantes rastreios não invasivos tradicionais têm taxas de falsos positivos de aproximadamente $5 \%$ e taxas de deteção que variam entre $50 \%$ e $95 \%$ dependendo da estratégia utilizada. $1,8,10-11$

Outro dos métodos frequentemente utilizados em Portugal para o rastreio de aneuploidias é o rastreio bioquímico do segundo trimestre, que deve ser realizado entre a $14^{\text {a }}$ semana e a $22^{\text {a }}$ semana mais seis dias de gestação e que é utilizado quando não se consegue realizar o rastreio combinado do primeiro trimestre por já ter ultrapassado as 14 semanas de gestação. Neste caso é utilizada a determinação serológica materna de quatro substâncias, sendo elas a alfa-fetoproteína (AFP), $\beta$-HCG, estradiol ( $\mu \mathrm{E} 3$ ) e inibina-A. Este método tem a vantagem de também poder determinar o risco de defeitos do tubo neural por usar a AFP. ${ }^{1}$

$\mathrm{O}$ rastreio sequencial passo-a-passo, em que primeiro é feito o rastreio combinado do primeiro trimestre e depois se utilizam os seus resultados para também calcular o risco do rastreio bioquímico do segundo trimestre, é outro método disponível.

Recentemente surgiram novos testes não invasivos baseados na pesquisa e análise de fragmentos de ADN livre fetal (que, apesar do nome, não deriva do feto, mas da camada de citotrofoblasto das vilosidades coriónicas) no sangue materno que, segundo os seus promotores, terão uma performance muito superior aos tradicionalmente utilizados (maior sensibilidade, especificidade e possibilidade de serem realizados numa idade gestacional mais precoce). ${ }^{12}$

No Sistema Nacional de Saúde Português é disponibilizado à maioria das grávidas o rastreio combinado do primeiro trimestre. ${ }^{4,9}$ As que cumprem os requisitos clínicos para realizar diagnóstico pré-natal devem ser encaminhadas para os cuidados de saúde secundários. Estes critérios estão publicados em Diário da República, no Despacho n. ${ }^{\circ}$ 5411/97, e são: idade materna superior a 35 anos; filho anterior portador de cromossomopatia; progenitor portador de cromossomopatia equilibrada; alteração dos valores dos marcadores serológicos maternos; risco elevado de recorrência de doença genética não cromossómica e risco elevado de efeito teratogénico (infecioso, medicamentoso, outro). ${ }^{13}$

Com esta revisão pretendeu-se responder à questão se será este teste uma opção enquanto rastreio de primeira linha, pelo que o objetivo deste estudo foi rever a evidência disponível sobre a performance, limitações e custo-efetividade do teste pré-natal não invasivo baseado na medição de ADN livre fetal em comparação com os testes tradicionais.

\section{MÉTODOS}

Foi realizada uma pesquisa de meta-análises (MA), revisões sistemáticas (RS), ensaios clínicos controlados e randomizados (ECR) e guidelines publicados nas bases de dados Guidelines Finder, Trip Database, CMA-Infobase, The Cochrane Library, DARE, Bandolier e PubMed, entre janeiro de 2013 e julho de 2018, nas línguas inglesa, portuguesa e espanhola. Foram utilizados os termos de pesquisa non-invasive prenatal test e cell-free fetal DNA.

Foram incluídos na revisão artigos que cumprissem os seguintes critérios: a) População: grávidas; b) Intervenção: teste pré-natal não invasivo para pesquisa de trissomias através de análise de ADN livre fetal; 
TABELA 1. Chave para a classificação de evidência e atribuição de graus de recomendação utilizando a escala da Canadian Task Force on Preventive Health Care

Qualidade da avaliação da evidência

I: Evidência obtida a partir de pelo menos um ensaio clínico apropriadamente randomizado.

II-1: Evidência obtida a partir de ensaios controlados bem desenhados sem randomização.

II-2: Evidência obtida a partir de coortes bem desenhados (prospetivo ou retrospetivo) ou estudos caso-controlo, preferencialmente provenientes de mais do que um centro ou grupo de investigação.

II-3: Evidência obtida a partir de comparações entre tempos ou espaços com ou sem intervenção. Resultados dramáticos em estudos não-controlados (como os resultados do tratamento com penicilina em 1940) também podem ser incluídos na categoria.

III: Opiniões de autoridades respeitadas, baseadas na experiência clínica, estudos descritivos ou relatórios de comités de especialistas.

\section{Classificação das recomendações}

A: Existe evidência de boa qualidade para recomendar a atividade clínica preventiva.

B: Existe evidência de moderada qualidade para recomendar a atividade clínica preventiva.

C: A evidência existente é conflituosa e não permite realizar recomendações a favor ou contra a atividade clínica preventiva. No entanto, outros fatores podem influenciar a tomada de decisão.

D: Existe evidência de moderada qualidade para recomendar contra a atividade clínica preventiva.

E: Existe evidência de boa qualidade para recomendar contra a atividade clínica preventiva.

I: A evidência é insuficiente (em quantidade ou qualidade) para fazer uma recomendação, no entanto, outros fatores podem influenciar a tomada de decisão. c) Comparação: testes não invasivos tradicionais para deteção de trissomias; d) Outcome: performance (sensibilidade, falsos positivos, valor preditivo positivo), limitações e custo-efetividade. Foram excluídos os artigos que não cumpriam os objetivos ou os critérios de inclusão e os artigos repetidos.

Os autores utilizaram a escala Canadian TASK Force (Tabela 1) na avaliação dos estudos e atribuição dos níveis de qualidade da evidência e classificação de recomendação.

\section{RESULTADOS}

Da pesquisa obtiveram-se 517 artigos. No fluxograma da Figura 1 encontra-se descrito o processo de seleção dos artigos. Foram incluídos os seguintes artigos: quatro RS com MA, duas RS e seis guidelines.

Das quatro RS com MA incluídas nesta revisão (Tabela 2), a primeira foi efetuada por Taylor-Phillips e colaboradores em 2015. Analisou 11 estudos caso-controlo, 29 coortes e um estudo com tipologia pouco clara. O outcome avaliado foi a validade da pesquisa e aná- lise de $\mathrm{ADN}$ livre fetal para rastreio das trissomias 21 , 18 e 13. A maioria dos estudos (30) avaliou gravidezes únicas e tinha como amostra grávidas com alto risco para aneuploidias. Apenas seis estudos tiveram uma amostra da população obstétrica no geral. O risco de viés foi elevado na maioria dos estudos. Em 29 estudos mais de $20 \%$ da população foi testada no segundo ou terceiro trimestre, quando a fração de $\mathrm{ADN}$ livre fetal é mais alta, logo, aumentando a validade do teste. A sensibilidade do teste foi maior para a trissomia 21 e menor para a 18 e 13 . Foi mais baixa quando o teste era realizado no primeiro trimestre, na população em geral e em gravidezes gemelares, e mais alta quando realizado em grávidas de alto risco. Apesar das técnicas de análise de ADN livre fetal utilizadas variarem entre estudos, tal não pareceu afetar a validade do teste. A percentagem de testes que falhou variou entre $0 \%$ a $12,7 \%$. Existe alguma evidência de que a percentagem de falha é maior quando a idade gestacional é mais baixa ou na presença de trissomia. A aplicabilidade dos resultados foi motivo de preocupação, porque os dados das 
populações às quais seria aplicado o rastreio são poucos. Na população em geral, onde a prevalência de trissomia é mais baixa, o valor preditivo positivo do teste seria mais baixo e o número de falsos positivos maior. $^{14}$

A MA de Mackie e colaboradores (Tabela 2) incluiu apenas estudos de coorte para diminuir o risco de viés, sendo poucos aqueles que avaliavam a trissomia 13. O outcome avaliado foi a validade da pesquisa e análise de ADN livre fetal. Nos estudos avaliados nesta MA a descrição das causas e implicações de falsos positivos, falsos negativos e resultados inconclusivos foi escassa. Alguns estudos não implementaram controlo de qualidade nas diferentes etapas, o que dificulta a interpretação e comparação dos dados. O facto de diferentes tipos de técnicas terem sido utilizadas para a análise de ADN livre fetal nas trissomias 21 e 18 não teve efeito significativo, assim como o risco populacional. Dos estudos que descreveram resultados inconclusivos (14 em 31 na trissomia 21; 12 em 24 na trissomia 18; e todos os 16 estudos para a trissomia 13) e falsos resultados, apenas alguns referem as possíveis causas, como falha do teste, pequena fração de ADN livre fetal na amostra ou mosaicismo. Novamente realçam o impacto da baixa

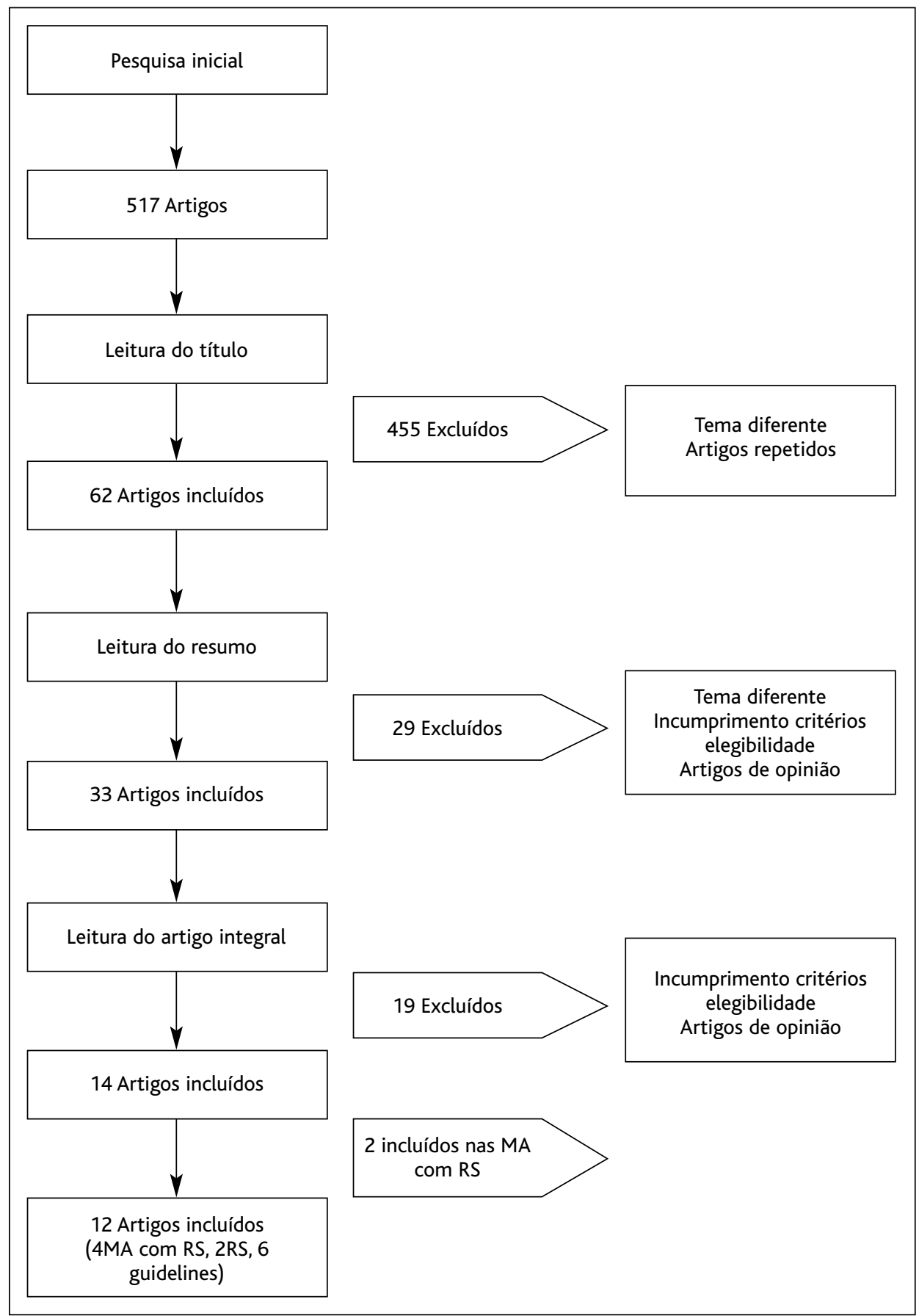

Figura 1. Fluxograma da seleção dos artigos.

Legenda: MA com RS = Meta-análises com revisões sistemáticas; RS = Revisões sistemáticas .

prevalência de aneuploidias no valor preditivo positivo e percentagem de falsos positivos do teste. Esta MA confirma a existência de evidência suficiente que 


\section{TABELA 2. Revisões sistemáticas com meta-análises}

\begin{tabular}{|c|c|c|c|c|}
\hline Referência & $N^{\circ}$ de estudos & Resultados & Comentários & NE* \\
\hline $\begin{array}{l}\text { Taylor-Phillips, } \\
\text { et al. }(2015)^{14}\end{array}$ & $\begin{array}{l}41 \text { estudos ( } 29 \text { coortes, } \\
11 \text { caso-controlo, } 1 \text { com } \\
\text { tipologia pouco clara) } \\
\text { No estudos: } \\
\text { T21=41 } \\
\text { T18=37 } \\
\text { T13=30 } \\
1997 \text { - Fevereiro } 2015\end{array}$ & $\begin{array}{l}\text { T21: S 99,3\% (98,9\%-99,6\%) } \\
\text { T18: S 97,4\% (95,8\%-98,4\%) } \\
\text { T13: S 97,4\% (86,1\%-99,6\%) } \\
\text { Especificidade para as três: } \\
\text { 99,9\% (99,9\%-100\%) } \\
\text { População geral: } \\
\text { T21: S 95,9\% E 99,9\% } \\
\text { T18: S 86,5\% E 99,8\% } \\
\text { T13: S 77,5\% E > 99,9\% } \\
\text { População de alto risco: } \\
\text { T21: S 97\% E 99,7\% } \\
\text { T18: S 93\% E99,7\% } \\
\text { T13: S 95\% E 99,9\% }\end{array}$ & $\begin{array}{l}\text { A avaliação de qualidade identificou } \\
\text { elevado risco de viés nos estudos } \\
\text { incluídos e a avaliação dos gráficos } \\
\text { em funil viés de publicação. } \\
\text { Análise dividida em grávidas de alto } \\
\text { risco e população geral }\end{array}$ & II-2 \\
\hline $\begin{array}{l}\text { Mackie, et al. } \\
(2016)^{15}\end{array}$ & $\begin{array}{l}117 \text { coortes } \\
1997-\text { Abril } 2015\end{array}$ & $\begin{array}{l}\text { T21: S 99,4\% (98,3\%-99,8\%) } \\
\text { T18: S 97,7\% (95,2\%-98,9\%) } \\
\text { T13: S 90,6\% (82,3\%-95,8\%) } \\
\text { T21: E 99,9\% (99,9\%-100\%) } \\
\text { T18: E 99,9\% (99,8\%-100\%) } \\
\text { T13: E 100\% (99,9\%-100\%) }\end{array}$ & $\begin{array}{l}\text { Incluíram grávidas com diferentes } \\
\text { tipos de risco para aneuploidias. } \\
\text { A população incluía apenas } \\
\text { gravidezes únicas. }\end{array}$ & $11-2$ \\
\hline $\begin{array}{l}\text { Iwarsson, et al. } \\
(2016)^{16}\end{array}$ & $\begin{array}{l}32 \text { estudos } \\
\text { ( } 23 \text { coortes } \\
9 \text { caso-controlo) } \\
1998 \text { - Abril } 2015\end{array}$ & $\begin{array}{c}\text { População geral: } \\
\text { T21: S 99,3\% (95,5\%-99,9\%) } \\
\text { E 99,9\% (99,8\%-99,9\%) } \\
\text { T18 e T13: S e E não calculado p/ } \\
\text { poucos estudos } \\
\text { População de alto risco: } \\
\text { T21: S 99,8\% (98,1\%-99,9\%) } \\
\text { T18: S 97,7\% (95,8\%-98,7\%) } \\
\text { T13: S } 97,5 \%(81,8 \%-99,7 \%) \\
\text { E 99,9\% ( } 99,8 \%-99,9 \%) \text { para as } \\
3 \text { trissomias } \\
\text { Falsos positivos: } 2,7 \%-30 \% \\
\text { Falsos negativos: < } 0,01\end{array}$ & $\begin{array}{l}\text { Primeira meta-análise que usou } \\
\text { GRADE para avaliar a qualidade. } \\
\text { Análise dividida em grávidas de alto } \\
\text { risco e população geral. }\end{array}$ & $11-2$ \\
\hline $\begin{array}{l}\text { Gil, et al. } \\
(2017)^{17}\end{array}$ & $\begin{array}{l}35 \text { estudos } \\
\text { Janeiro } 2011- \\
\text { Dezembro } 2017\end{array}$ & $\begin{array}{l}\text { T21: S 99,7\% (99,1\%-99,9\%) } \\
\text { T18: S 97,9\% (94,9\%-99,1\%) } \\
\text { T13: S 99,0\% (65,8\%-100\%) } \\
\text { Falsos positivos de 0,04\% para as } \\
\text { 3 trissomias }\end{array}$ & $\begin{array}{l}\text { Maioria dos estudos só incluía } \\
\text { grávidas de alto risco. } \\
\text { Excluídos caso-controlo. } \\
\text { Análise bi-variada. }\end{array}$ & $1 \mathrm{II}-2$ \\
\hline
\end{tabular}

Legenda: NE = Nível de evidência; $\mathrm{T} 21$ = Trissomia 21; T18 = Trissomia 18; T13 = Trissomia 13; ADN = Ácido desoxirribonucleico; S = Sensibilidade; $\mathrm{E}=$ Especificidade.

Nota: Intervalos de confiança calculados a $95 \%$.

*Nível de evidência atribuído pelas autoras. 
suporta a validade e reprodutibilidade da pesquisa e análise de ADN livre fetal, permitindo a sua introdução na prática clínica como teste de rastreio. No entanto, ainda não é claro em que tipo de rastreio deve ser integrado (como primeira linha ou sequencial contingente). ${ }^{15}$

A MA de Iwarsson e colaboradores (Tabela 2) incluiu 23 estudos coorte e nove caso-controlo. Foi a primeira MA a usar a escala GRADE para determinar a confiança nas estimativas combinadas da sensibilidade e especificidade. Os autores concluíram, com evidência de qualidade moderada, que o teste baseado em ADN livre fetal tem boa performance como teste de rastreio para a trissomia 21 na população geral. Para as trissomias 13 e 18, os dados são muito limitados pelo que mais estudos são necessários. Como vantagens deste teste referem a deteção de mais gravidezes com aneuploidias e a diminuição do número de grávidas que necessitam de um exame invasivo. O maior fator limitativo continua a ser o preço que, pelo menos, é o dobro do rastreio combinado. Os autores referem que apesar da taxa de falsos positivos ser baixa, as grávidas devem confirmar o resultado do teste baseado no ADN livre fetal com um teste invasivo, se considerarem colocar fim à gravidez. ${ }^{16}$

Na MA de Gil e colaboradores (Tabela 2), publicada em 2017, foram excluídos os estudos caso-controlo, uma vez que estes tendem a sobrestimar a performance dos testes e porque eram os estudos mais antigos utilizando tecnologias piores. Os autores utilizaram a análise bivariada porque este modelo de análise tem em conta não só a heterogeneidade entre estudos na taxa de deteção e na taxa de falsos positivos, mas também a correlação negativa entre estas duas estatísticas. Os autores concluíram que, nas gravidezes únicas, o rastreio baseado no ADN livre fetal tem performance superior aos testes tradicionais para as trissomias $21,18 \mathrm{e} 13$. No entanto, a implementação deste teste como rotina deve ser cautelosa, uma vez que os estudos englobados na MA têm alto grau de viés, podendo sobrestimar a performance do teste. Os autores defendem que o rastreio sequencial contingente poderá levar a uma elevada taxa de deteção e diminuição dos testes invasivos. Assim, o resultado do rastreio combinado estratificaria a população em três grupos: alto risco, que necessitava de testes invasivos; risco intermédio, que beneficiaria do teste com ADN livre fetal; e baixo risco, que não necessitava de nenhuma intervenção subsequente. ${ }^{17}$

As duas RS (Tabela 3), que preenchiam critérios de inclusão para o presente artigo, são ambas de 2017 e abordam o impacto económico do teste com ADN livre fetal em comparação com os testes tradicionais. A RS de Nshimyumukizat e colaboradores englobou 16 estudos comparativos de ADN livre fetal versus testes de rastreio convencionais (12 relativos ao rastreio universal e 13 ao rastreio contingente), publicados entre 2012 e 2015. A maioria dos artigos ( $n=11)$ considerou, na sua análise de custos, apenas os custos diretos do rastreio e/ou diagnóstico das aneuploidias. Relativamente à qualidade dos artigos analisados pelos autores, a maioria era de qualidade moderada. Para comparar o custo-efetividade do teste de ADN livre fetal, os autores construíram dois diagramas com quatro quadrantes, onde o eixo das abcissas representa o nível de outcome e o eixo das ordenadas o custo e compararam o uso do teste de ADN livre fetal como rastreio universal versus estratégias de rastreio convencionais e ainda o teste de ADN livre fetal como rastreio sequencial contingente versus testes de rastreio convencionais. O teste de ADN livre fetal (como rastreio universal ou sequencial contingente) era considerado dominante se o estudo o localizasse no canto inferior direito do diagrama (alto outcome e baixo custo) e era considerado dominado se colocado no canto superior esquerdo do diagrama (baixo outcome alto custo). Quando colocados nos outros quadrantes (canto superior direito ou canto inferior esquerdo), os autores analisaram os rácios de custo-efetividade. Na comparação entre o teste de ADN livre fetal universal versus o teste de rastreio convencional, quatro dos 12 estudos consideraram que o teste de ADN livre fetal domina o teste de rastreio convencional. Um estudo considera que o teste de ADN livre fetal é dominado entre utilizadoras dos 20-39 anos. Nove estudos consideraram que ele é efetivo, mas aumenta os custos e sete estudos consideraram que o teste de ADN livre fetal como rastreio universal não é uma estratégia custo-efetiva. Um estudo considerou que é uma estratégia custo-efetiva para utilizadoras com 40 ou mais anos. Em relação à comparação do teste de $\mathrm{ADN}$ livre fetal como rastreio sequencial contingente versus o teste de rastreio convencional, três estudos consideraram que o teste de ADN livre fetal como rastreio sequencial 
TABELA 3. Revisões sistemáticas: impacto económico

\begin{tabular}{|c|c|c|c|c|c|}
\hline Referência & $\mathbf{N}^{\circ}$ de estudos & Intervenção & Resultados & Comentários & NE* \\
\hline $\begin{array}{l}\text { Nshimyumukizat, } \\
\text { et al. }(2017)^{18}\end{array}$ & $\begin{array}{l}16 \text { estudos } \\
\text { Janeiro } 2009 \\
\text { - Janeiro } 2016\end{array}$ & $\begin{array}{l}\text { Teste ADN fetal vs testes } \\
\text { tradicionais (marcadores } \\
\text { bioquímicos com ou sem } \\
\text { translucência da nuca } \\
\text { e/ou idade maternal) }\end{array}$ & $\begin{array}{l}12 \text { estudos: } R \text {. universal } \\
\text { Teste ADN livre fetal } \\
\text { como teste de } 1^{\text {a }} \text { linha } \\
\text { não é custo-efetivo na } \\
\text { maioria dos estudos. } \\
13 \text { estudos: R. contingente } \\
\text { 3: custo-efetivo } \\
\text { 9: neutro } \\
\text { 2: não custo-efetivo } \\
\text { A maioria dos estudos } \\
\text { tem baixa qualidade. }\end{array}$ & 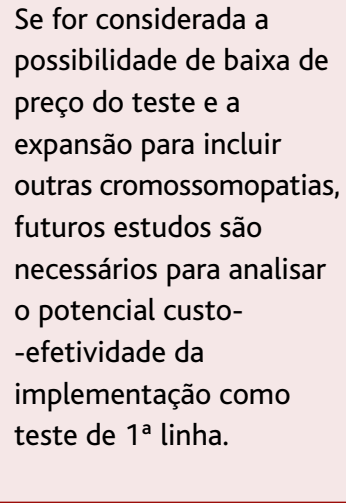 & III \\
\hline $\begin{array}{l}\text { Garcia Pérez, } \\
\text { et al. }(2017)^{19}\end{array}$ & $\begin{array}{l}12 \text { Estudos } \\
\text { (4 Europeus) } \\
\text { Janeiro } 2009 \\
\text { - Janeiro } 2016\end{array}$ & $\begin{array}{l}\text { Teste AND fetal vs testes } \\
\text { tradicionais }\end{array}$ & $\begin{array}{l}9 \text { estudos: R. universal } \\
\text { Mais eficaz, mas mais } \\
\text { caro, com aumento muito } \\
\text { grande do custo. } \\
\frac{9 \text { estudos: R. contingente }}{\text { Resultados heterogéneos. }}\end{array}$ & $\begin{array}{l}\text { Custo-efetividade do } \\
\text { rastreio contingente é } \\
\text { incerto enquanto o } \\
\text { rastreio universal não é } \\
\text { atualmente custo-efetivo. }\end{array}$ & III \\
\hline
\end{tabular}

Legenda: $N E$ = Nível de evidência; $R$ = Rastreio; $A D N=$ Ácido desoxirribonucleico.

*Nível de evidência atribuído pelas autoras.

contingente é dominante, um considerou que era dominante entre as idades 20-39 anos, mas para as utilizadoras com 40 ou mais anos era a estratégia com menos custo, mas que produzia menos Quality-Adjusted Life Years e, por isso, não é custo-efetiva. Dois estudos consideraram-na com menos custos e menos efetiva. Seis estudos consideraram que aumentou os custos e os benefícios, sendo por isso custo-efetiva, desde que o aumento do custo por outcome não supere a vontade de pagar. Os autores concluíram que, quando comparamos o custo-efetividade do teste de ADN livre fetal com os testes convencionais, os resultados são heterogéneos, dependendo da metodologia e contexto do estudo, e a sua interpretação deve ser cautelosa. As variáveis incertas mais comuns foram: preço unitário do teste de ADN livre fetal; os cut-offs de risco para o rastreio na prática atual; taxas de resposta ao rastreio (de primeira e segunda linha); e taxas de resposta ao rastreio diagnóstico invasivo e respetivos custos. Apesar disso, o teste de rastreio com $\mathrm{ADN}$ livre fetal parece não ser custo-efetivo para programas de rastreio públicos universais, exceto se o seu preço descer substancialmente e se se considerar a inclusão de outras cromossomopatias no teste. Assim, os autores consideraram que, por agora, uma abordagem sequencial contingente é mais custo-efetiva. ${ }^{18}$

A RS de García-Pérez e colaboradores (Tabela 3) englobou 12 estudos, quatro deles europeus, publicados entre 2012 e 2016, que comparavam as estratégias de rastreio com testes convencionais versus estratégias de rastreio com o teste de ADN livre fetal, universal ou sequencial contingente, com o objetivo de avaliar o custo-efetividade em termos de números de casos de aneuploidias detetadas e de número de técnicas invasivas com possibilidade de perda fetal (amniocentese, biópsia de vilosidades coriónicas) evitadas, avaliando os estudos com a mesma estratégia da RS de Nshimyumukizat, onde a utilização do teste de ADN livre fetal é considerada dominante ou dominada. Os estudos obtiveram resultados heterogéneos, especialmente os 
que usavam o teste de ADN livre fetal como rastreio sequencial contingente, parecendo que os resultados dependem das seguintes variáveis: cut-offs do teste de rastreio, idade das mulheres, perspetiva do utilizador/sistema de saúde e taxa de adesão ao teste de rastreio sequencial contingente. $\mathrm{O}$ teste de ADN livre fetal como rastreio universal parece ser mais efetivo que as abordagens convencionais, mas o custo é superior, sendo uma estratégia que de momento não é custo-efetiva para a população em geral. Os autores referem que uma das vantagens do rastreio com teste de ADN livre fetal como rastreio sequencial contingente é a diminuição dos testes invasivos e, consequentemente, menores

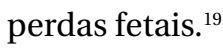

No Canadá, a guideline da Society of Obstetricians and Gynaecologists of Canada (Tabela 4) refere que o teste pré-natal não invasivo utilizando ADN livre fetal para rastreio de trissomia 21, 18 e 13 pode ser uma opção disponível para as grávidas com alto risco para aneuploidia fetal em vez da amniocentese. $\mathrm{O}$ aconselhamento destas mulheres antes da realização do exame deve incluir a discussão das suas limitações, nomeadamente o facto de não ser um teste diagnóstico, tendo uma maior taxa de falsos positivos comparativamente a estes (motivo pelo qual não deve levar a uma interrupção da gravidez sem ser feito antes um teste confirmatório invasivo) e ser inconclusivo em algumas situações. Se teste positivo, o resultado deve ser confirmado com teste diagnóstico invasivo. Esta guideline menciona que apesar de a pesquisa de ADN livre fetal para rastreio de trissomias ser promissora, enquanto teste de rastreio, são necessários mais estudos em grávidas de médio risco e uma redução significativa dos custos do teste antes de substituir os métodos atuais de rastreio. $^{2}$

A Society for Maternal-Fetal Medicine Consult Series (Tabela 4) conclui que as candidatas ótimas para realização de teste pré-natal não invasivo, utilizando ADN livre fetal para rastreio de trissomia 21, 18 e 13 por rotina, são aquelas com fatores de risco para as aneuploidias descritas. Esta sociedade não recomenda a utilização do teste para a pesquisa de microdeleções por ter um valor preditivo positivo baixo e utilidade clínica pouco clara. ${ }^{20}$

$\mathrm{O}$ American College of Obstetricians and Gynaecologists (Tabela 4) aconselha que a todas as mulheres seja oferecido o rastreio de aneuploidias. A escolha do teste depende de várias características, como desejo de informação antes do parto, história obstétrica e familiar, número de fetos e disponibilidade de recursos. Refere-se que nenhum teste é superior em todas as características, que cada um tem vantagens e desvantagens, dependendo a escolha das características e desejos da utente e da disponibilidade dos testes na região em questão. Às mulheres que recebem um resultado negativo de um teste de rastreio não devem ser oferecidos mais testes de rastreio por aumentar a probabilidade de falsos positivos. ${ }^{21}$

O American College of Medical Genetics and Genomics (Tabela 4) refere que as grávidas devem ser informadas de que o teste pré-natal não invasivo utilizando ADN livre fetal para rastreio de trissomia 21, 18 e 13 é o mais sensível. Se o resultado for positivo devem ser referenciadas a um geneticista treinado e ser-lhes oferecido teste diagnóstico. Se o resultado for inconclusivo devem igualmente ser encaminhadas para teste diagnóstico. Menciona-se que a performance do teste poderá ser alterada se aplicado a grávidas com menos de 10 semanas de gestação, obesas, na presença de mosaicismo, gravidez múltipla, gémeo não evolutivo, neoplasia materna, dissomia uniparental ou consanguinidade. Nestas situações deve ser oferecido outro teste, que não a pesquisa de $\mathrm{ADN}$ livre fetal. $\mathrm{O}$ facto de poder ser realizado cedo na gestação (a partir das 10 semanas) constitui uma vantagem em comparação com os testes tradicionais. Tal como a Society for Maternal-Fetal Medicine Consult Series, não recomenda a utilização deste teste para pesquisa de outro tipo de aneuploidias. ${ }^{8}$

A Joint Society of Obstetricians and Gynaecologists of Canada-Canadian College of Medical Geneticists (Tabela 4) menciona que, de momento, oferecer a análise de ADN livre fetal a todas as grávidas como teste de primeira linha do rastreio não é financeiramente viável na maioria das regiões. Refere-se, no entanto, que oferecer este teste num modelo de rastreio sequencial contingente seria mais viável, no qual a pesquisa de ADN livre fetal seria oferecida a mulheres com um rastreio convencional positivo ou de alto risco, que desejassem evitar um teste diagnóstico invasivo. Neste modelo, o cut-off teria de ser ajustado para se obter uma taxa de deteção e falsos positivos semelhantes às obtidas com a pesquisa de $\mathrm{ADN}$ livre fetal como rastreio de 


\begin{tabular}{|c|c|c|}
\hline Referência & Recomendação & NE e FR* \\
\hline $\begin{array}{l}\text { Society of Obstetricians and } \\
\text { Gynaecologists of Canada }(2013)^{2}\end{array}$ & $\begin{array}{l}\text { O teste pré-natal não invasivo utilizando ADN fetal para rastreio de } \\
\text { trissomia } 21,18 \text { e } 13 \text { pode ser uma opção disponível para as grávidas de } \\
\text { alto risco em vez da amniocentese. }\end{array}$ & II-2A \\
\hline $\begin{array}{l}\text { Society for Maternal-Fetal Medicine } \\
\text { Consult Series }(2015)^{20}\end{array}$ & $\begin{array}{l}\text { Candidatas ótimas para teste pré-natal não invasivo utilizando ADN fetal: } \\
\text { idade superior a } 35 \text { anos na altura do parto; alterações ecográficas } \\
\text { sugestivas de T21, T18 ou T13. }\end{array}$ & II-2A \\
\hline $\begin{array}{l}\text { American College of Obstetricians } \\
\text { and Gynaecologists }(2016)^{21}\end{array}$ & $\begin{array}{l}\text { A pesquisa de AND livre fetal não é um teste diagnóstico, pelo que não } \\
\text { deve ser usado como tal. } \\
\text { Se resultado positivo ou inconclusivo, deve ser-lhes oferecido } \\
\text { aconselhamento genético e teste diagnóstico. }\end{array}$ & I-A \\
\hline $\begin{array}{l}\text { American College of Medical } \\
\text { Genetics and Genomics }(2016)^{8}\end{array}$ & $\begin{array}{l}\text { As grávidas devem ser informadas de que o teste pré-natal não invasivo } \\
\text { utilizando ADN fetal para rastreio de trissomia } 21,18 \text { e } 13 \text { é o mais sensível. }\end{array}$ & $I I-2 A$ \\
\hline $\begin{array}{l}\text { Joint Society of Obstetricians and } \\
\text { Gynaecologists of Canada-Canadian } \\
\text { College of Medical Geneticists }(2017)^{22}\end{array}$ & $\begin{array}{l}\text { No presente, oferecer a pesquisa e análise de ADN fetal a todas as grávidas } \\
\text { como teste de primeira linha do rastreio não é financeiramente viável na } \\
\text { maioria das províncias. } \\
\text { Oferecer este teste num modelo de rastreio sequencial contingente é uma } \\
\text { opção mais viável. }\end{array}$ & III-A \\
\hline $\begin{array}{l}\text { Royal Australian and New Zealand } \\
\text { College of Obstetricians and } \\
\text { Gynaecologists }(2018)^{23}\end{array}$ & $\begin{array}{l}\text { O rastreio bioquímico combinado do primeiro trimestre e a pesquisa de } \\
\text { ADN livre fetal são ambos testes aceitáveis como rastreio de primeira } \\
\text { linha de cromossomopatias no primeiro trimestre, dependendo a escolha } \\
\text { de um ou de outro dos recursos locais e das características demográficas e } \\
\text { individuais das grávidas. }\end{array}$ & III-B \\
\hline
\end{tabular}

Legenda: $\mathrm{NE}=$ Nível de evidência; FR = Força de recomendação; $\mathrm{ADN}=$ Ácido desoxirribonucleico.

*Força de recomendação atribuída pelas autoras.

primeira linha (especialmente quando se consideram as taxas de resultados inconclusivos ou falsos negativos da pesquisa de ADN livre fetal). Esta guideline aponta também para o facto de que, embora a sensibilidade e a especificidade do teste serem semelhantes numa população de alto risco, o valor preditivo positivo é mais baixo na população em geral devido à menor prevalência de aneuploidias fetais, o que significa que existirão mais falsos positivos. Por exemplo, para um teste com sensibilidade de $93 \%$ para trissomia 21 e especificidade de $99,8 \%$, dada a prevalência de $1 / 1000$ para síndroma de Down numa população de mulheres com 25 anos, apenas uma em cada três mulheres com um resultado anormal terão um feto com anomalia, isto é, um valor preditivo positivo de $33 \%$, enquanto numa população de mulheres de 40 anos, em que a prevalência é de $1 / 75$, o valor preditivo positivo será de $87 \% .^{22}$
O Royal Australian and New Zealand College of Obstetricians and Gynaecologists (Tabela 4) refere que a pesquisa de ADN livre fetal ou o rastreio bioquímico combinado do primeiro trimestre são ambos testes aceitáveis como rastreio de primeira linha de aneuploidias no primeiro trimestre, enquanto no segundo trimestre quer a pesquisa de $\mathrm{ADN}$ livre fetal quer o rastreio quádruplo são igualmente aceitáveis, dependendo em ambos os casos a escolha de um ou de outro dos recursos locais e das características demográficas e individuais das grávidas. As grávidas devem receber aconselhamento antes de serem submetidas à pesquisa de ADN livre fetal, nomeadamente quanto à possibilidade de resultados inesperados. A opção de efetuar a pesquisa de ADN livre fetal como teste de segunda linha, se risco aumentado de aneuploidia após teste de primeira linha, deve ser discutido com todas as mulheres, 
devendo estas receber aconselhamento por um profissional de saúde com treino adequado. Antes da tomada de decisões definitivas, como o término da gravidez, deve ser utilizado um teste diagnóstico. ${ }^{23}$

\section{CONCLUSÕES}

Perante a evidência disponível, a pesquisa de ADN livre fetal no sangue materno, apesar de ter uma melhor sensibilidade e menor número de falsos positivos para as trissomias 21, 18 e 13 em comparação com os testes tradicionais, não é custo-efetiva como exame de primeira linha no rastreio universal, sendo o custo-efetividade do rastreio sequencial contingente ainda incerto (III-C qualidade de evidência fraca, recomendação fraca). Os estudos existentes são ainda de fracamoderada qualidade para que se possa tomar uma decisão com uma evidência robusta. Para as grávidas de alto risco poderá ser uma opção como exame de primeira linha no rastreio de aneuploidias (II-2A qualidade de evidência moderada, recomendação forte).

É ainda importante considerar que o teste tem uma menor performance, apresentando maior percentagem de resultados falsos positivos ou resultados inconclusivos se for realizado antes das 10 semanas de gestação; em mulheres obesas ( $20 \%$ de falha se o peso for superior a $114 \mathrm{Kg}$ e $50 \%$ de falha se o peso for superior a $158 \mathrm{Kg}$ ); na presença de mosaicismo (10 a 15\% do ADN livre fetal presente no sangue materno é de origem placentária); neoplasia materna; gravidez múltipla; gémeo não evolutivo; dissomia uniparental; ou na presença de consanguinidade. ${ }^{8,14-15,20}$

A proporção e a qualidade de ADN livre fetal presente na amostra pode condicionar igualmente a performance do teste (uma baixa fração fetal na amostra pode ocorrer em aproximadamente $4 \%$ dos casos, associada, nomeadamente, a risco de aneuploidia, peso elevado ou idade gestacional inferior a 10 semanas). Por este motivo, todos os laboratórios deveriam incluir nos relatórios a fração fetal e especificar a razão pela qual o resultado foi inconclusivo, o que nem sempre acontece., ${ }^{8,15,20,22}$

$\mathrm{O}$ facto da idade gestacional, gravidez múltipla e a presença de gémeo não evolutivo, por exemplo, poderem interferir com a qualidade do teste faz com que seja indispensável a realização de uma ecografia de boa qualidade prévia ao exame. Note-se também que o teste de rastreio de aneuploidias realizado atualmente, ao contrário da pesquisa e análise de ADN livre fetal, pode detetar outras alterações para além das aneuploidias, como a pré-eclâmpsia, a restrição do crescimento fetal ou defeitos do tubo neural, pelo que deve continuar a ser oferecida às grávidas a ecografia e, eventualmente, a pesquisa de alfa-fetoproteína. ${ }^{22}$

$O$ facto de nem todos os estudos compararem os testes pré-natais não invasivos com testes de diagnóstico, de existirem diferentes cut-offs para rastreio positivo (risco aumentado) definidos por cada laboratório e de não haver estudos comparativos entre laboratórios constituem limitações. ${ }^{8,22}$

É importante referir que o valor preditivo positivo deste teste varia de acordo com a idade e o tipo de população. A generalização dos valores preditivos positivos e negativos encontrados nos estudos avaliados encontra-se limitada, porque a prevalência da trissomia na maioria dos estudos não é representativa da população em geral, na medida em que muitos estudaram populações de alto risco. O ideal, aquando da obtenção de um resultado positivo, seria a disponibilização do valor preditivo positivo específico do utente ou o derivado da população em questão, quando o primeiro não puder ser determinado, para uma melhor interpretação, o que nem sempre acontece. .,14-15,22 $^{\text {. }}$

A utilização de diferentes metodologias para análise de ADN livre fetal nos vários estudos constitui uma limitação. Independentemente desta limitação, a taxa de deteção de síndroma de Down foi superior à dos testes tradicionais. A validade clínica do teste não é tão boa para as trissomias 13 e 18; no entanto, a sensibilidade é superior à dos testes tradicionais, com um menor número de falsos positivos, como acontece para a trissomia 21. Estes dados relativos à trissomia 13 e 18 poderão ser menos fiáveis em comparação aos obtidos para a trissomia 21, por evidência de menor qualidade devido à escassez de dados, pequeno número de casos de trissomia 13 e 18 nas amostras incluídas nos estudos e maior grau de viés. $8,16-17,20,22$

Dado o valor demonstrado da pesquisa e análise de fragmentos de ADN livre fetal no sangue materno em grávidas com risco aumentado para aneuploidias, este teste poderia ser considerado uma opção para as grávidas com risco aumentado com base em alterações nos testes de rastreio tradicionais e que quisessem evitar testes de diagnóstico invasivos..$^{20,22}$ 
Antes deste método substituir os métodos de rastreio universal atuais ou de poder ser considerado como um método de rastreio sequencial contingente previamente à realização de testes invasivos a grávidas de risco intermédio-alto, seriam necessários mais estudos de custo-efetividade bem desenhados e que avaliassem a performance de diferentes estratégias de rastreio, tendo em conta que nos estudos até agora efetuados foram poucos aqueles cuja população era constituída por grávidas de baixo ou médio risco para aneuploidias. Se o custo do teste baixar e passar a incluir outras cromossomopatias, novos estudos serão necessários para analisar o potencial custo-efetividade como teste de primeira linha. ${ }^{14-15,17-19,22}$

Em todos os casos, este teste exige aconselhamento pré-teste acerca dos seus benefícios/limitações, o acesso a ecografia de boa qualidade prévia ao exame e a necessidade de referenciação e acompanhamento especializado, se o teste for positivo, por um geneticista. ${ }^{16,20-22}$

Fica a questão de que tipo de abordagem deve ser oferecida às mulheres quando a pesquisa e análise de fragmentos de ADN livre fetal é positiva e o teste de diagnóstico é negativo.

\section{REFERÊNCIAS BIBLIOGRÁFICAS}

1. Henriques $S$. Rastreio pré-natal de cromossomopatias e defeitos do tubo neural: como actuar? [Prenatal screening for chromosomal abnormalities and neural tube defects: How should this be done?]. Rev Port Clin Geral. 2009;25(3):320-31. Portuguese

2. Langlois S, Brock JA, The Genetics Committee. Current status in noninvasive prenatal detection of Down syndrome, trisomy 18 , and trisomy 13 using cell-free DNA in maternal plasma. J Obstet Gynaecol Can. 2013;35(2):177-81.

3. Hall H. Baby's DNA in mom's blood: noninvasive prenatal testing. Science-Based Medicine [Internet]; 2013 Sep 17 [cited 2018 Oct 8]. Available from: https://sciencebasedmedicine.org/babys-dna-in-momsblood-noninvasive-prenatal-testing/

4. Direção-Geral da Saúde. Exames ecográficos na gravidez de baixo risco: norma n. ${ }^{\circ}$ 023/2011, de 29/09/2011, atualizada em 21/05/2013. Lisboa: DGS; 2013.

5. Hayes Inc. Noninvasive Prenatal Testing (NIPT) for fetal aneuploidy [homepage]. University of York: Centre for Reviews and Dissemination; 2013. Available from: https://www.crd.york.ac.uk/crdweb/ShowRecord .asp? ID =32013000829\&ID=32013000829

6. Reis AP, Azevedo S, Lebre A, Valente E, Lima L, Cunha A. Alterações morfológicas e bioquímicas na trissomia 21 [Morphological and biochemical changes in trisomy 21]. Arq Med. 2015;29(4):88-92. Portuguese

7. European Surveillance of Congenital Anomalies. Prevalence charts and tables [homepage]. Brussels: European Commission; 2018 [updated 2019 Dec 10; cited 2018 Oct 9]. Available from: https://eu-rd-platform.jrc.ec.europa.eu/eurocat/eurocat-data/prevalence_en

8. Gregg AR, Skotko BG, Benkendorf JL, Monaghan KG, Bajaj K, Best RG, et al. Noninvasive prenatal screening for fetal aneuploidy, 2016 update: a position statement of the American College of Medical Genetics and Genomics. Genet Med. 2016;18(10):1056-65.

9. Direção-Geral da Saúde. Programa nacional para a vigilância da gravidez de baixo risco. Lisboa: DGS; 2015. ISBN 9789726752332

10. Alldred SK, Takwoingi Y, Guo B, Pennant M, Deeks JJ, Neilson JP, et al. First trimester ultrasound tests alone or in combination with first trimester serum tests for Down's syndrome screening. Cochrane Database Syst Rev. 2017;3(3):CD012600.

11. Santorum M, Wright D, Syngelaki A, Karagioti N, Nicolaides KH. Accuracy of first-trimester combined test in screening for trisomies 21,18 and 13. Ultrasound Obstet Gynecol. 2017;49(6):714-20.

12. Sachs A, Blanchard L, Buchanan A, Norwitz E, Bianchi DW. Recommended pre-test counseling points for noninvasive prenatal testing using cell-free DNA: a 2015 perspective. Prenat Diagn. 2015;35(10):96871.

13. Despacho n.o 5411/97, de 6 de agosto. Diário da República. $2^{a}$ Série (180):9509-10.

14. Taylor-Phillips S, Freeman K, Geppert J, Agbebiyi A, Uthman OA, Madan $J$, et al. Accuracy of non-invasive prenatal testing using cell-free DNA for detection of Down, Edwards and Patau syndromes: a systematic review and meta-analysis. BMJ Open. 2016;6(1):e010002.

15. Mackie FL, Hemming K, Allen S, Morris RK, Kilby MD. The accuracy of cell-free fetal DNA-based non-invasive prenatal testing in singleton pregnancies: a systematic review and bivariate meta-analysis. BJOG. 2017;124(1):32-46.

16. Iwarsson $E$, Jacobsson B, Dagerhamn J, Davidson T, Bernabé E, Arnlind $\mathrm{MH}$. Analysis of cell-free fetal DNA in maternal blood for detection of trisomy 21, 18 and 13 in a general pregnant population and in a highrisk population: a systematic review and meta-analysis. Acta Obstet Gynecol Scand. 2017;96(1):7-18.

17. Gil MM, Accurti V, Santacruz B, Plana MN, Nicolaides KH. Analysis of cell-free DNA in maternal blood in screening for aneuploidies: updated meta-analysis. Ultrasound Obstet Gynecol. 2017;50(3):302-14.

18. Nshimyumukiza L, Menon S, Hina H, Rousseau F, Reinharz D. Cell-free DNA noninvasive prenatal screening for aneuploidy versus conventional screening: a systematic review of economic evaluations. Clin Genet. 2018;94(1):3-21.

19. García-Pérez L, Linertová R, Álvarez-de-la-Rosa M, Bayón JC, Imaz-Iglesia I, Ferrer-Rodríguez J, et al. Cost-effectiveness of cell-free DNA in maternal blood testing for prenatal detection of trisomy 21, 18 and 13: a systematic review. Eur J Health Econ. 2018;19(7):979-91.

20. Society for Maternal-Fetal Medicine. \#36: Prenatal aneuploidy screening using cell-free DNA. Am J Obstet Gynecol. 2015;212(6):711-6.

21. Committee on Practice Bulletins - Obstetrics, Committee on Genetics, Society for Maternal-Fetal Medicine. Practice bulletin no. 163: screening for fetal aneuploidy. Obstet Gynecol. 2016;127(5):e123-37.

22. Audibert F, De Bie I, Johnson JA, Okun N, Wilson RD, Armour C, et al. No. 348-Joint SOGC-CCMG Guideline: update on prenatal screening for fetal aneuploidy, fetal anomalies, and adverse pregnancy outcomes. 
J Obstet Gynaecol Can. 2017;39(9):805-17.

23. HGSA/RANZCOG Joint Committee on Prenatal Diagnosis and Screening. Prenatal screening and diagnostic testing for fetal chromosomal and genetic conditions [Internet]. The Royal Australian and New Zealand College of Obstetricians and Gynaecologists; 2018. Available from: https://ranzcog.edu.au/RANZCOG_SITE/media/RANZCOG-MEDIA/ Women\%27s\%20Health/Statement\%20and\%20guidelines/ClinicalObstetrics/Prenatal-screening_1.pdf?ext=.pdf

\section{CONFLITO DE INTERESSES}

Os autores declaram não ter quaisquer conflitos de interesse.

\section{FINANCIAMENTO}

O trabalho relatado neste manuscrito não foi objeto de qualquer tipo de financiamento externo.

\author{
ENDEREÇO PARA CORRESPONDÊNCIA \\ Telma Monteiro Miragaia \\ E-mail: telmamiragaia@hotmail.com \\ https://orcid.org/0000-0001-8695-6860
}

Recebido em 08-12-2018

Aceite para publicação em 16-02-2020

\section{ABSTRACT}

\section{NON-INVASIVE PRENATAL TESTS FOR ANEUPLOIDIES SCREENING: AN EVIDENCE-BASED REVIEW}

Objectives: We aim to compare the performance, limitations, and cost-effectiveness of non-invasive prenatal cell-free fetal DNA test (cff-DNA), with the traditional tests in pregnant women.

Data Sources: Guidelines Finder, TRIP database, CMA-Infobase, The Cochrane Library, DARE, Bandolier, and PubMed.

Review methods: We searched for meta-analysis, systematic reviews, controlled and randomized clinical trials, and clinical guidelines published in English, Portuguese, and Spanish languages between January 2013 and July 2018. Searched terms: "non-invasive prenatal test" and "cell-free fetal DNA". The Canadian TASK Force scale was used to assess the studies' quality and to assign the level of evidence and strength of recommendation. The selected outcome was performance, limitations, and cost-effectiveness of the test.

Results: The search provided 517 articles. Twelve met the inclusion criteria: two were systematic reviews, four were systematic reviews with meta-analysis, and six were clinical guidelines. The cff-DNA test has better performance to detect trisomy 21 , 18 , and 13 than traditional tests. Its clinical validity is higher for trisomy 21. However, it's not a diagnostic test. Therefore, a positive or inconclusive result must be confirmed by a diagnostic test and the pregnant women referred for genetic counseling. Conclusions: The cff-DNA test could be an option to detect trisomy 21, 18, and 13 in the high-risk pregnant women, rather than amniocentesis. If the test result is positive or inconclusive, it must be confirmed by an invasive test (II-2A). It has some limitations like test performance before 10 weeks of gestational age, maternal obesity, multiple pregnancies, or maternal neoplasia. In these situations, pregnant women should be studied. Currently, the cost-effectiveness of the contingent screening is uncertain, and the universal screening isn't cost-effective (III-C).

Keywords: Non-invasive prenatal test; Cell-free fetal DNA. 